\title{
ABSTRACTS
}

\section{COMPARING CHILD PRODUCT SAFETY CONCERNS WITH INJURY INCIDENTS: DOES THE EVIDENCE SUPPORT THE RESPONSE?}

doi:10.1136/injuryprev-2012-040580a.22

${ }^{1} \mathrm{~K}$ McKenzie*, ${ }^{1} \mathrm{~J}$ Limbong, ${ }^{2} \mathrm{D}$ Strachan. ${ }^{1}$ Centre for Accident Research and Road Safety, Queensland University of Technology, Queensland, Australia; ${ }^{2}$ Product Safety, Office of Fair Trading, Department of Justice and Attorney-General, Queensland, Australia

Background Efficient effective child product safety (PS) responses require data on hazards, injury severity and injury probability. PS responses in Australia largely rely on reports from manufacturers/ retailers, other jurisdictions/regulators, or consumers. The extent to which reactive responses reflect actual child injury priorities is unknown.

Aims/Objectives/Purpose This research compared PS issues for children identified using data compiled from PS regulatory data and data compiled from health data sources in Queensland, Australia.

Methods PS regulatory documents describing issues affecting children in Queensland in 2008-2009 were compiled and analysed to identify frequent products and hazards. Three health data sources (ED, injury surveillance and hospital data) were analysed to identify frequent products and hazards.

Results/Outcomes Projectile toys/squeeze toys were the priority products for PS regulators with these toys having the potential to release small parts presenting choking hazards. However, across all health datasets, falls were the most common mechanism of injury, and several of the products identified were not subject to a PS system response. While some incidents may not require a response, a manual review of injury description text identified child poisonings and burns as common mechanisms of injuries in the health data where there was substantial documentation of product-involvement, yet only $10 \%$ of PS system responses focused on these two mechanisms combined.

Significance/contribution to the field Regulatory data focused on products that fail compliance checks with 'potential' to cause harm, and health data identified actual harm, resulting in different prioritisation of products/mechanisms. Work is needed to better integrate health data into PS responses in Australia. 